\title{
Review
}

\section{Gestational, Perinatal and Neonatal Loss: Emotional and Psychological Consequences on Mothers, Fathers and Healthcare Professionals}

\author{
Fabiola Ortiz-Aparicio, MA, MHS; ;osé R. Rodríguez-Gómez, MD, PhD; Maribella Gonzalez-Viruet, PhD \\ Department of Clinical Psychology, Albizu University, San Juan 0090 I, Puerto Rico \\ ${ }^{*}$ Corresponding author \\ Fabiola Ortiz-Aparicio, MA, MHS \\ Department of Clinical Psychology,Albizu University, San Juan 0090I, Puerto Rico; E-mail: f.o.aparicio@gmail.com
}

\section{Article Information}

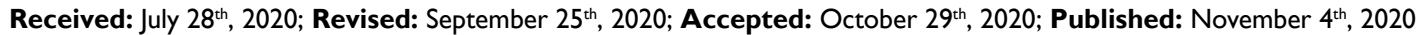

\section{Cite this article}

Ortiz-Aparicio F, Rodríguez-Gómez JR, Gonzalez-Viruet M. Gestational, perinatal and neonatal loss: Emotional and psychological consequences on mothers, fathers and healthcare professionals. Soc Behav Res Pract Open J. 2020; 5(2): 43-52. doi: 10.17140/SBRPOJ-5-127

\section{ABSTRACT}

The current article contains compilation of significant contributions done by theorists over the years about the phenomenon of perinatal loss. The objective of this paper is to provide information about important emotional and psychological consequences on parents who suffer stillbirth. This article addresses identity issues of the mother, father, and their relationship as a couple. It also provides information on the psychological, emotional, and legal aftermath of healthcare professionals who assist during the process of loss.

\section{Keywords}

Patient-child; Healthcare professionals; Child death.

\section{INTRODUCTION |}

$\mathrm{T}$ he death of a loved one can extraordinarily affect those who suffer the loss, with negative consequence on the psyche. Some psychologists have indicated that the psychological trauma of loss is analogous to the traumatic experience of being severely burned or wounded. ${ }^{1,2}$ The loss of a loved one is, in itself, a painful event. Beyond being a painful event, it is categorized by one of the most complex and stressful experiences a parent can suffer, ${ }^{3-5}$ and could be considered a devastating event. ${ }^{6}$ This type of loss is especially intense when the loss of an unborn child is involved. It is peculiar different from other types of losses; due to the unnatural process that negates the creative biological cycle for which parents-to-be are not prepared. Also, this type of loss is not acknowledged by society, which may influence a mother to remain silent about her suffering, increasing mental and emotional distress. ${ }^{7}$ This matter is not recent; over the years, authors have made significant contributions to our understanding of the subject, suggesting the need for specialized attention.

de Madinabeitia ${ }^{8}$ refers to the first article about the suffering of stillborn parents published in 1959. The article reviewed the difficulties that an obstetrician had when facing fetal death before, during, and after childbirth. It demonstrated that the doctors' suggestion that as soon as the mother woke up from anesthesia, she would be told about the birth process but avoid mentioning seeing or holding the baby. The doctor would suggest that the mother have another baby as quickly as possible, giving her happiness and self-confidence.

In 1968, Bourne drafted an article on the psychological effects of the deceased baby in the women and their doctors. He suggests that the deceased could become a type of "blind spot" for the professionals (professional blind spot) that go through the experience, pretending that it had not occurred at all. The medical professionals kept absolute silence about the occurrence and would sedate the mother in the stillbirth with the intention of "avoiding the pain" of seeing the baby lifeless. When the mother woke up, the body had already been taken out of sight. As previously mentioned, the most common recommendation for these cases was to suggest a new pregnancy for parents to forget the passing. 
Further, Kennell et $\mathrm{al}^{9}$ published about the grief of neonates. The paper highlighted distinctive elements such as sadness, poor appetite, difficulty sleeping, and concern with the lost child, and the inability to return to the activity of daily life. Benfield et $\mathrm{al}^{10}$ studied the responses of grief in first-births of neonates in vital risk, and in that same year, work on the specific management of stillbirth was published.

Peppers et $\mathrm{ll}^{11}$ proposed other elements of grief: difficulty concentrating, anger, guilt, refusal to accept reality, temporary confusion, exhaustion, lack of energy, depression, and repetitive dreams with the deceased baby. After this contribution, the interest in attending the perinatal loss according to its particularities began.

Callahan et $\mathrm{al}^{12}$ stated that the perinatal loss is different from others because of the "refusal to talk about what happened because the cause of the death is often unknown and because of the intense guilt it generates." Addressing this issue, as described, was called the unrecognized bereavement. That same year, Kirkley-Best et a ${ }^{13}$ pointed out "without proper study, professionals are destined to follow the fashions of popular books about grief, without meeting the specific needs of the parents of stillbirths." To facilitate the elaboration of grief and reduce the guilt it generates in the parents, they recommended the birthright to see and hold their baby. In addition, they proposed to develop support groups for those affected.

Leppert et $\mathrm{al}^{14}$ documented that women experience intense grieving reactions during the first six weeks after the loss. The results reflected that guilt seems to be the predominant feature in the sample's grieving response, with manifestations regarding what they did or did not do. In a study conducted, the mothers reported that they thought that having performed behaviors such as exercising, having sex, suffering a fall, or smoking, appeared to be the possible causes of loss, resulting in self-guilt behaviors. However, the literature indicates that physical exercise or sexual intercourse during the pregnancy process, without precautionary contraindications, is not considered a risk factor.

Rando ${ }^{15}$ considered the importance of paying attention to losses, especially those lacking social recognition. This type of recognition does not receive the benefit of status and social support that is usually given to people who suffer from any loss of a loved one. At that time, it was common to think that a woman who loses a child in the gestational stage of pregnancy would be "relieved" or "exonerated" of the grieving process in comparison to those who suffer a neonatal loss. However, in a study by Linberg ${ }^{16}$ with a sample of 20 women who had experienced loss between 12 and 24-weeks of pregnancy/gestation, it was observed that they had the same grieving characteristics as those who had suffered a neonatal loss. Some of the symptoms were: despair, anguish, guilt, social isolation, loss of control, feelings of depersonalization, somatization, anxiety about death, courage, and recurring concerns. The following will present a compilation of authors who contributed to the loss theme and their respective contributions. For instance, Lindemann ${ }^{17}$ provide and publish a complete description of the concept of grief, his contribution was based on collaborating and working with relatives who were lost in the nightclub fire called Coconut Grove in 1942 where 500 people died.

An anonymous author published in 1959, the first article on the suffering of a perinatal loss of a first born. This article reported the difficulties that an obstetrician had when facing fetal death before, during, and after childbirth. At that time, the doctors used to recommend that the mother have another baby as soon as possible, with the aim of pursuing "happiness" and "replacing." the deceased baby. Bourne ${ }^{18}$ contributed to the physiological effects of stillbirth in women and their doctors. He wrote about the "professional blind spot," in which professionals pretended that nothing had happened. Kennel et $\mathrm{al}^{9}$ published about the grief of newborns and highlighted feelings experienced by the mother such as sadness, changes in appetite, alteration of sleep patterns and inability to perform the functions of daily living. Moreover, Benfield et $\mathrm{al}^{10}$ studied the responses of grief in the firstborn of the neonates. Another author that provides more information on the topic was Rando ${ }^{15}$ proposed six phases in the bereavement process: (1) recognize the loss, (2) react to separation by remembering, re-experience the deceased, (3) remember and experience pain, feel, identify, accept and find ways of expression for psychological reactions to loss, (4) give up the attachment with the deceased and previous vision of the world, (5) readjusting to the new world adaptively without forgetting the above and developing a new relationship with the absent as well as new ways of being in the world, (6) reinvest energy in the present and look to the future. This author also pointed out the importance of losses that lack social recognition, such as perinatal loss. Finally, Neimeyer ${ }^{19}$ proposed a new vision of grief. Defined grief by reconstructing the meaning of the loss, and highlighting the active process. Also, he indicated that the grieving process is determined not only by the emotions, but by the relational context and the meanings the grieving person gives to the grief and to the restructuring after the loss. The author established the following steps in the process: (a) avoidance, (b) assimilation, and (c) accommodation. The contributions made by experts on the subject reviels some of the consequences that the loss can cause to those involved. In addition to the aforementioned sequels, such losses can disrupt other related areas such as motherhood, fatherhood, and couples' relationship.

\section{MATERNITY AND LOSS}

Women who suffer the loss of their baby may experience a variety of symptoms such as shame, guilt, and a sense of failure. ${ }^{20}$ Of all these symptoms, guilt is the most common because they feel they could have done something to prevent the death of their. ${ }^{21-26}$

This feeling of guilt can come from the social perception in which parents are expected to be the ones who take care of their children and provide them with protection. ${ }^{27}$ In addition to the feeling of guilt, both the mother and the father may experience feeling, shame, desire to die, and suffer the stigma because of their feel they. ${ }^{28,29}$

The intensity of the symptoms that each person experiences can be varied; individuals who are predisposed to feel shame and guilt often experience symptoms with higher intensity. ${ }^{26,29}$ Dur- 
the loss of the baby has occurred in the last stages of gestation, and (4) the number of losses experienced.

Women expecting a first child can manifest feelings of fear related to the pregnancy. For example, in a study with firsttime mothers, it was found that they show greater worry and attachment with their baby compared with a group of mothers with experiences of pregnancy. ${ }^{27}$

\section{PATERNITY AND LOSS}

When a baby dies, generally, it is perceived that the mother suffers the loss in a way more severe and intense than the father. ${ }^{46}$ However, this loss can affect the father as well. The impact on the father can be related to the level of involvement that he has had during the gestational and perinatal process.

The participation of men in the process of the pregnancy, childbirth, and puerperium, has changed over the years. A few years ago, fathers faced paternity when their first child was born, or sometimes, when the child had already grown up. Men used to practice a traditional paternity, which involved the responsibility of being family's economic provider. This type of paternity excludes fathers from involvement in the care and early development of their children, awarding women such tasks. ${ }^{47,48}$ This social construction has led to the avoidance of affective involvement with the pregnancy, and suppression of feelings in front of others. ${ }^{48,49}$ However, through the years, a "new sense of paternity" in which a man no longer is considered only as provider of the family but also is involved in tasks related to domestic works and the care and development of his children Mota et $\mathrm{al}^{48}$ and Ochoa et al ${ }^{49}$ mentioned that this could be due to "new form of configuration of families in which they present new practices of parental care, instead of traditional roles. These changes have allowed a different distribution of task and responsibilities". ${ }^{48}$

Several researchers ${ }^{48,51,52}$ have indicated that men, especially the younger generations, have increased their participation in terms to the caring of children. Through the years, it has become common to see generations of young men participating in prenatal care activities, preparation childbirth, and involvement in the immediate puerperium. A father has been able to be present at labor and at times, has been able to cut the umbilical cord and even witness the expulsion of the placenta. Studies ${ }^{48}$ indicate that a father who witnesses his child's birth has the opportunity to obtain a more intimate relationship with his child that those who " $d o$ not witness it." These authors explained that this breaks the cultural expectations that minimize the importance of men in a women's gestational process due to ignorance about the emotional and cognitive aspects of fatherhood.

Like women, men also face critical psychological processes during the gestational process of their partners. Maldonado-Duran et $\mathrm{a}^{53}$ indicate that parents accomplish some psychological tasks during the pregnancy. These are the following: (1) resolve each other's ambivalence towards pregnancy and the future child, (2) establish an attachment with the fetus, (3) redefine the identity of the man becoming a father, (4) achieve internal conviction that 
he can take care of the fetus first and then the baby, (5) give support to his partner and prepare a psychological and real "nest" for the child and (6) assume the new responsibilities as a father.

Regarding the emotional aspect, investigations ${ }^{54-56}$ indicate that men may experience fears related to the behavior that their partners will exhibit during childbirth, their ability to play the new role, and their relationship as a couple. This tends to happen when a man assumes this role for the first time in his life.

The fear parents face may increase when they receive the news that the child they expect has low probability to live or does not have vital signs. This news can have an emotional impact on men, especially Latin men. Osores ${ }^{57}$ has mentioned that for a Latin man, the paternity is motivated by the desire to perpetuate his family and kin through their descendants. When a man experiences the loss of his child, it involves the loss of his transcendence and his future. Besides, the lack of social recognition of the loss makes it more challenging due to the lack of social support that can prolong the mourning process.

Palaces et $\mathrm{al}^{58}$ indicate that men that confront the death of their child will go through the following phases: (1) paralysis, (2) longing, (3) disorganization, and (4) reorganization. The first phase refers to when a man feels distant from others. He usually has thoughts of disbelief, thinking "this cannot be happening" or "this cannot be true." Also, he can suffer changes in sleep, appetite, or experience difficulty concentrating. The second phase is about the need and the desire to become a father. Some of them who get exposed to friends who have children and do activities with them can feel excluded. The third phase is the longest one and is characterized by lack of control, anxiety, and hopelessness. The fourth and last phase is about acceptance and personal repurposing of one's life. It is assumed that this phase can take a couple of years. It is essential to point out that these phases are not universal. Also, if these manifestations occur, they do not necessarily happen in a particular order because each loss is an individual phenomenon. Therefore, they can only be utilized as a reference point for educational purposes and bring perspective to the process of loss.

When a father experiences a loss and faces the grieving process in terms of its the impact on the "self," it could be less difficult than what the mother experiences. ${ }^{59}$ Fathers, unlike mothers find themselves excluded from the differentiation process. Nonetheless, when fatherhood is valued by the father he also experiences a sense of frustration and feelings of failure in protecting his child when the loss occurs.

Lang et $\mathrm{al}^{60}$ indicate that men who experience mourning can manifest aggressiveness, anxiety, somatic and psychotic symptoms. Other than these behaviors, suppression of feelings tend to occur to conform to social expectations and to show themselves as "emotionally strong."

A study done with 3,503 fathers of a stillborn baby, showed that half suppressed their feelings because they believed society wanted them to forget their baby and move on to another pregnancy as soon as possible. ${ }^{61}$ When fathers suppress their feel- ings, stress begins to mount and can create maladaptive behaviors that prolong the natural grieving process of a loss. These responses can prevent the father from seeking help. At times, men find themselves immersed in supporting their partners while feeling alone and fearful and avoid asking for support. Literature suggests that man's natural suppression of feelings works as a defense to conform to society's expectations. It could cause risky behavior that may even lead to legal problems. Conway et $\mathrm{al}^{62}$ suggests that some of these legal issues tend to be the use and abuse of alcohol and other narcotics. Additionally, men may worry about the behavior of the mother during childbirth and their capacity to perform as a father and partner. ${ }^{54-56}$

\section{THE COUPLE'S RELATIONSHIP AFTER THE LOSS}

The death of a child can influence the relationship between the couple. Literature shows that stillbirth is a risk factor in the rupture of a relationship. ${ }^{63}$ A study conducted by Gold et al, ${ }^{64}$ Koopmans et $\mathrm{al}^{65}$ revealed that stillbirth increases the probability of a divorce by $40 \%$. In another study conducted by Shreffler et al, ${ }^{66}$ it was found that relationships are four times more likely to dissolve after a stillbirth than relationships that do not suffer perinatal loss. ${ }^{59} \mathrm{It}$ should be noted that these studies do not consider other factors in the relationship.

However, couples that face emotional and psychological challenges of a stillbirth can develop a stronger relationship. ${ }^{67}$ This may be due to the different elements that support the relationship such as communication, trust and emotional closeness. Perinatal loss creates vulnerability in the couple, and with the right mix of the elements mentioned above can evolve a better bond within the relationship. Also, couples that rely on each other during the grieving process tend to report fewer intense grief reactions, and a higher level of satisfaction in the relationship. ${ }^{68-70}$

Barr $^{71}$ indicated that fathers have fewer symptoms of anxiety than mothers. This outcome does not mean that the loss is less significant to them; it could mean that they may have different ways of grieving. Fathers also tend to have a delayed response to the event of a stillbirth. They usually carry out funeral arrangements and handle the final processes. In the aftermath, they tend to submerge themselves in work to provide for the family. They also tend to fabricate a false sense of "strength" to try to support their significant other. ${ }^{71}$ This creates in fathers a sense of responsibility for the emotional stability of the relationship. ${ }^{5}$ Nevertheless, due to the fact the men and women mourn in different ways, a sense of loneliness overcomes the process because each of them may not quite comprehend what the other is feeling.

A study by Cacciatore ${ }^{28}$ and Campbell et al, ${ }^{73}$ revealed a relationship between self-condemnation, shame, guilt, and parental mental health. The study was done online with 2,232 women who suffered a stillbirth and were followed over three years. It revealed that $24.6 \%$ of women reported self-condemnation and a significant increase in depression and anxiety. ${ }^{74} \mathrm{Barr}^{26}$ conducted a study with couples who suffered perinatal loss, and it showed that parents felt guilty for surviving their children. This sense of guilt will eventually is reflected in the grieving process. 
Parents who suffer a stillbirth also manifest frustration with the lack of understanding and support of healthcare professionals who assist in the process, as well as with the lack of support from society. ${ }^{70,75-77}$ This can affect later pregnancies creating a fragile emotional state and feelings of isolation and/or can influence negatively the development and behavior of the child. ${ }^{78-81}$

Around $50 \%$ of couples that suffer stillbirths give birth within a year. ${ }^{73,82}$ When a couple gives birth after one or several perinatal losses it is expected that the couple would be overcome with happiness. However, literature shows that feelings of anxiety, depression, and postpartum stress arise in comparison to couples that have never experienced a perinatal loss. This may be due to the uncertainty about their protective role. Besides, some parents may still be dealing with the effects of previous stillbirths and the grief related to perinatal losses. ${ }^{76}$ In some cases, the crisis resolution turns out to be maladaptive and individuals can meet the criteria for persistent complex bereavement disorder. Couples who meet the criteria for this type of diagnosis will experience greater psychological vulnerability. This process requires specialized attention addressing parents' psycho-emotional status to ensure their well-being as much as the well-being of the expected new child. They also would require a safe space to overcome and process their grief.

Grieving process tends to mitigate the negative impact of the loss. Any individual that goes through a significant loss will face this process. From the psychoanalitic perspective established by Freud, ${ }^{45}$ grief is not a product of a pathological condition; therefore, with the passing of time it should improve. Due to some unique conditions of perinatal loss, first-time parents could suffer serious repercussions that could profoundly affect their well-being to the point of needing clinical intervention depending on the symptoms the individual has.

\section{CLINICAL SEQUELAE}

According to the Diagnostic and Statistical Manual of Mental Disorders, ${ }^{83}$ uncomplicated bereavement (V62.82) is defined as a normal reaction to the death of a loved one, in which some individual afflictions range in symptoms of major depression episode with feelings of deep sorrow, significant weight loss/gain, insomnia or hypersomnia, psychomotor retardation or agitation, and recurrent thoughts of death. Other definitions from prominent expert authors in bereavement ${ }^{2,15,17,19,45}$ define bereavement as the reaction to the loss of a loved one, as well as to the loss of something material, or symbolic, depending on the attachment to the object. Authors agree that bereavement should be considered as a life-altering experience, but should also be considered as a common or expected process in the circle of life in the sense that most individuals will face bereavement in their lifetimes. According to the DSM- $5{ }^{83}$ there are some similarities and differences between uncomplicated bereavement and clinical depression. Both conditions deal with feelings of guilt. During uncomplicated bereavement, feelings of guilt may persist as well as a sense of emptiness. These feelings are associated to the deceased and tend to improve with the passing of time (e. g., days or weeks), but they come back occasionally. Different from clinical depression, where sadness and negative thoughts persist, during uncomplicated bereavement at times, the individual has positive and even joyful feelings. During the clinical depression there is the inability of experiencing happiness or pleasure. Through this episode, the depressed mood an individual is experiencing is not associated with thoughts or specific worries, contrary to uncomplicated bereavement.

The guilt is the common denominator between uncomplicated bereavement and clinical depression. Regardless of the culpability experienced in both diagnoses, it can be differentiated through the content of thought. During uncomplicated bereavement, guilt is associated with surviving a lost child while in clinical depression, it is associated with thoughts of low self-worth and pessimistic rumination. Generally, the self-esteem of an individual in clinical depression is highly affected due to an overwhelming feeling of poor self-concept and self-deprecation. Usually, in uncomplicated bereavement, individual's self-esteem is not impacted. Nevertheless, some mother's self-esteem can be impacted during the grieving process. $^{29}$

Another element that differentiates both diagnoses is the perception of death experienced by the individual. In both diagnoses, there are thoughts about death or dying. However, in clinical depression it is usually centered on ending one's life due to a sense of helplessness, unworthiness, or the inability to handle the pain caused by the depression. Meanwhile, in uncomplicated bereavement, feelings of death are focused around dying to reunite the deceased loved one. ${ }^{83}$ When the process of grief is mishandled, the individual's capacity to find a sense of life and the ability to make future plans, is diminished; this, characterizes the persistent complex bereavement disorder.

According to the DSM- $5,^{83}$ the persistent complex bereavement disorder specifies criteria $\mathrm{A}$ through $\mathrm{E}$. Criterion $\mathrm{A}$ requires that the individual has experienced the death of a loved one; criterion $\mathrm{B}$ requires the presence of one of four symptoms related to yearning, longing, and sorrow; criterion $C$ requires six of 12 symptoms demonstrating reactive distress or functional impairment, and; criterion $\mathrm{E}$ requires that distress or impairment is outside of socio-cultural norms. Persistent complex bereavement disorder requires that symptoms be present for at least twelve months and that they are not better accounted for by major depressive disorder, generalized anxiety disorder, or post-traumatic stress disorder (PTSD). ${ }^{84}$

Some individuals could manifest symptoms that belong to post-traumatic stress disorder. Generally, an individual that is grieving may not experience PTSD ${ }^{85}$ However, individuals with pre-existing medical conditions could suffer PTSD, and might have a higher risk of experiencing persistent complex bereavement disorder. $^{86-89}$

The attention given by a healthcare professional to women during pregnancy, birth, and postpartum, has direct and indirect consequences. ${ }^{15,90,91}$ From the moment the parents receive the news that their child does not have vital signs or has low probability of life, parents start feeling the distress caused by loss. According to the literature, the healthcare professional's delivery of the diagnos- 
tic has a bearing on the parents' emotional and psychological state. Healthcare professionals who do not receive specialized training or guidelines to properly manage perinatal loss can aggravate the anguish of loss. ${ }^{92}$ Even as the years go by, parents will remember who gives them the news, and even specific phrases such as "there is no heartbeat; the child is not compatible with life, among others." When professionals do not use the appropriate expressions and bed-side manners recommended by scientific literature, parents might develop a wrong perception about healthcare professionals.

In Puerto Rico, a newspaper article, ${ }^{93}$ presented an interview with mothers who suffered perinatal/postnatal loss. The article mentioned the dissatisfaction and discontent mothers and family members had with healthcare providers after suffering a loss. The mothers described the assistance received from professionals that worked in the hospital as "cold and inbuman." Mothers mentioned that the behaviors of the professionals caused additional distress to them and their families. ${ }^{93}$ The publication references Project 2560, known as Law 184, which demands proper procedures in a perinatal loss in every hospital and healthcare center in Puerto Rico. The Law establishes that mothers and their families must receive professional assistance according to their needs and should participate in the decision-making process of the loss.

There are countries that have examined mothers' perspective towards the healthcare provider's assistance. A study conducted in Sweden by Höglund et al, ${ }^{94}$ looked at the answers that mothers received to their questions from the healthcare professionals after the stillbirth. The results showed the following: $48.6 \% \mathrm{did}$ not receive any explanations on cause of deaths, $23.6 \%$ received a specific reason and $27.8 \%$, received vague or generic explanations. Participants described the service received from healthcare professionals as poor and their attitude as arrogant and evasive. Beyond the stillbirth process, it was found that these attitudes where also common during pregnancy. ${ }^{94}$

\section{LITIGATION AND PSYCHO-EMOTIONAL ASPECTS OF HEALTHCARE PROVIDERS |}

When the results of a medical procedure are negative, what is known as "bad outcome," and whether or not there is medical malpractice, it could end up in he courts. This may affect directly the medical personell involved. A questionnaire study Gold et al ${ }^{95}$ revealed that $75 \%$ of obstetricians who suffered a loss indicated that they felt a heavy burden, and 10\% considered abandoning their practice. In cases where malpractice occurs, professionals might experience psychological and somatic distress. ${ }^{96-98}$

Some of the initial emotions the medical community feels after litigation are guilt and shame. These responses reduce the sense of self-value. Professionals become afraid of being exposed publicly and getting rejected or diminished by their peers, commonly accompaied by feelings of guilt, anxiety, and depression. Receiving unexpected news about being sued could create a traumatic experience, "shock," emotional detachment, tension and insomnia, among others. ${ }^{98}$ In these cases, lawyers recommend the professionals not make any statements about the subject. When a professional follows this recommendation and does not talk about the event, they tend to suffer more significant distress because they cannot express their feelings about what happened. This could lead the professional to isolation, which tends to increase levels of stress and dysfunctional behavior.

\section{CONCLUSION}

Perinatal loss is a complex process and can influence the woman's cognitive and emotional functioning. Healthcare professionals need to follow proper guidelines to assist the woman, her partner, and their family in an effective way. Important aspects of cultural values, paternal and maternal identities, self-esteem and the different ways the couple could deal with grief, help minimize the effects of this experience. It is equally important to understand the symptoms associated with the loss, such as uncomplicated bereavement and clinical depression, to provide better management toward the healing process. The literature suggests that interventions should be aligned with the needs of the parents to avoid negative psycho-emotional sequelae for mothers and their families. Management based on scientific evidence can benefit healthcare professionals to effectively assist during perinatal loss. Healthcare professionals must acquire strategies that also benefit their own psychological and emotional well-being. For future investigations, it is recommended that the perception of healthcare professionals that assist women and their families in a stillbirth be explored more deeply. It is crucial to identify possible barriers that may influence women and their partner's participation about the decision-making process in the short time-frame surrounding birth. It is also recommended to explore different approaches that can benefit the emotional and psychological health of the women, their partners and the health professionals who assist them.

\section{CONFLICTS OF INTEREST}

The authors declare that they have no conflicts of interest.

\section{REFERENCES}

1. Engle P, Breaux C. Fathers' involment with children: Perspectives from developing countries. Social Policy Report, Society for Research in Child Development. 1998; 12(1): 1-24. doi: 10.1002/j.23793988.1998.tb00007.x

2. Bowlby EJJ. Attachment and Loss: Loss, Sadness and Depression. NY, USA: Basic Books; 1980.

3. Bonnano G, Kaltman S. The varieties of grief experience. Clin Psychol Rev. 2001; 2: 705-734. doi: 10.1016/s0272-7358(00)00062-3

4. Fish W. Differences in Grief Intensity in Bereaved Parents. IL, USA: Research Press Company; 1986.

5. Wing D, Clance P, Burge-Callaway K, Armistead L. Understanding gender difference in bereavement following the death of an infant: Implications for treatment. Psychotherapy. 2001; 38(1): 60-73. doi: 10.1037/0033-3204.38.1.60

6. Krosch D, Shakespeare G. Grief, traumatic stress and post-trau- 
matic growth in women who have experienced pregnancy loss. Psychol Trauma. 2017; 9: 425-433. doi: 10.1037/tra0000183

7. Murphy S, Cacciatore J. The psychological, social, and economic impact of stillbirth on families. Semin Fetal Neonatal Med. 2017; 22(3): 129-134. doi: 10.1016/j.siny.2017.02.002

8. de Madinabeitia APLG. Duelo perinatal: un secreto dentro de un misterio. Revista de la Asociación Española de Neuropsiquiatría. 2011; 31(1): 53-70. doi: 10.4321/S0211-57352011000100005

9. Kennell J, Slyter H, Klaus MH. The mourning response of parents to the death of a newborn infant. N Eng J Med. 1970; 283: 344-349. doi: 10.1056/NEJM197008132830706

10. Benfield D, Leib S, Vollman J. Grief response of parents to neonatal death and parents participation in deciding care. Pediatrics. 1978; 62: 171-177.

11. Peppers L, Knapps R. Maternal reactions to involuntary fetal infant death. Psychiatry. 1980; 43: 155-159. doi: 10.1080/00332747.1980.11024061

12. Callahan EJ, Brasted W, Granados JL. Life Span Developmental Psychology: Non-Normative Life Events. Massachusetts, USA: Academic Press; 1983.

13. Kirkley-Best E, Kellner K. The forgotten grief: a review of the psychology of stillbirth. Am J Orthopsychiatry. 1982; 52: 420-429. doi: 10.1111/j.1939-0025.1982.tb01428.x

14. Leppert P, Pahlka B. Grieving characteristics after spontaneous abortion: A management approach. Obstet Gynecol. 1984; 64 (1): 119-122.

15. Rando T. Parental Loss of a Child. IL, USA: Research Press; 1986.

16. Lindberg C. The grief response to mid-trimester fetal loss. $J$ Perinatol. 1992; 12(2): 158-163.

17. Lindemann E. Symptomatology and management of acute grief. Am J Psychiatry. 1944; 101: 141-148. doi: 10.1176/ajp.101.2.141

18. Bourne S. The psychological effects of stillbirths on women and their doctors. J R Coll Gen Pract. 1968; 16: 103-112.

19. Neimeyer RA. Searching for the meaning of the meaning: Grief therapy and the process of reconstruction. Death Stud. 2000; 24: 531-558. doi: 10.1080/07481180050121480

20. Wilson J, Drozdek B, Turkovic S. Post-traumatic shame and guilt. Trauma Violence Abuse. 2006; 7(2): 122-141. doi: $10.1177 / 1524838005285914$

21. Gaudet C. Pregnancy after perinatal loss: Association of grief, anxiety and attachment. Journal of Reproductive and Infant Psychology. 2010; 28: 240-251. doi: 10.1080/02646830903487342
22. McGuinness D, Coughlan B, Power S. Empty arms: Supporting bereaved mothers during the immediate postnatal period. Br J Midwifery. 2014; 22: 246-252. doi: 10.12968/bjom.2014.22.4.246

23. Stroebe MS, Hansson RO, Schut H, Stroebe W. Handbook of Bereavement Research and Practice: Advances in Theory and Intervention. NY, USA: American Psychological Association. 2008.

24. Vázquez C, Rosa D. Grief Therapy with Latinos. NY, USA: Springer Publishing Company; 2011.

25. Worden W. Grief Counseling and Grief Therapy, Fourth Edition: A Handbook for the Mental Health Practitioner. NY, USA: Springer Publishing Company; 2009.

26. Barr P. Negative self-conscious emotion and grief: An actor-partner analysis in couples bereaved by stillbirth or neonatal death. Psychology and Psychotherapy: Theory, Research and Practice. 2012; 85: 310-326. doi: 10.1111/j.2044-8341.2011.02034

27. Rivera V. Manual de intervencióngrupal con enfoque en el manejo de duelo por pérdidasprenatales, perinatales e infantiles. [dissertation]. Universidad Carlos Albizu; San Juan, Puerto Rico; 2015.

28. Cacciatore J. The unique experiences of women and their families after the death of a baby. Social Work in Health Care. 2010; 49: 134-148. doi: 10.1080/00981380903158078

29. Wonch P, Cacciatore J, Shreffler K, Pritchard K. The loss of self: The effect of miscarriage, stillbirth, and child loss on maternal self-esteem. Death Stud. 2017; 41(4): 226-235. doi: 10.1080/07481187.2016.1261204

30. Condon JT. The parental-fetal relationship: A comparison of male and female expectant parents. Journal of Psychosomatic Obstetrics and Gynecology. 1985; 4: 271-284. doi: 10.3109/01674828509016729

31. Goldbach K, Dunn D, Toedter L, Lasker J. The effect of gestational age and gender on grief after pregnancy loss. Am J Orthopsychiatry. 19991; 16: 461-446. doi: 10.1037/h0079261

32. Moulder C. Toward a preliminary framework for understanding pregnancy loss. Journal of Reproductive Health and Infant Psychology. 1994; 12: 65-67. doi: 10.1080/02646839408408869

33. Robinson M, Baker L, Nackeru L. The relationship of attachment theory and perinatal loss. Death Stud. 1999; 23: 257-270. doi: $10.1080 / 074811899201073$

34. Stryker S. Identity salience and role performance: The importance of symbolic interaction theory for family research. Journal of Marriage and the Family. 1968; 30: 558-564. doi: 10.2307/349494

35. Rogers S, White L. Satisfaction with parenting: The role of marital happiness, family structure, and parents' gender. Journal of Marriage and the Family. 1998; 60: 293-308. doi: 10.2307/353849 
36. Thoits P. On merging identity theory and stress research. Social Psychology Quarterly. 199; 154: 101-112. doi: 10.2307/2786929

37. Pérez J, Torrens A. The myth of motherhood and the role of stepmothers: An outlook of women who have delayed their motherhood. Journal of Divorce \& Remarriage. 2009; 50(3): 206-219. doi: 10.1080/10502550902717905

38. Raphael-Leff J. Psychological Processes of Childbearing. London, UK: Chapman \& Hall.; 1991.

39. Ulrich M, Weatherall A. Motherhood and infertility: Viewing motherhood through the lens of infertility. Feminism \& Psychology. 2000; 10(3): 323-336. doi: 10.1177/0959353500010003003

40. Heazel A, Siassakos D, Blencowe H, Burden C, Bhutta ZA, Cacciatore J, et al. Stillbirths: Economic and psychosocial consequences. Lancet. 2016; 387: 604-616. doi: 10.1016/S0140-6736(15)008363

41. Smith J. Identity development during the transition to motherhood: An interpretive phenomenological analysis. Journal of Reproductive and Infant Psychology. 1999; 17: 281-300. doi: $10.1080 / 02646839908404595$

42. Burke P. Identity processes and social stress. American Sociological Review. 1991; 56: 836-849. doi: 10.2307/2096259

43. Burke P. Social identities and psychosocial stress. In: Kaplan HB, ed. Psychosocial stress: Perspectives on Structure, Theory, Life-course, and Methods. Massachusetts, USA: Academic Press; 1996.

44. Leon IE. Perinatal loss: Choreographing grief on the obstetric unit. Am J Orthopsychiatry. 1992; 62: 7-8. doi: 10.1037/h0079315

45. Freud S. Mourning and melancholia. In: Strachey EJ, ed. The Standard Edition of the Complete Psychological Works of Sigmund Freud. London, UK: The Hogarth Press Limited; 1917: 243-258

46. Murray A, Terry J, Vance C, Battistutta D, Connolly Y. Effects of a program of intervention on parental distress following infant death. Death Stud.2000;24:275-305. doi:10.1080/074811800200469

47. Ortega M, Centeno O, Castillo M. Masculinidad y factoressocioculturalesasociadosa la paternidad: Estudio en cuatropaíses de Centroamérica; 2005. Web site. https://www.cepal.org/es/publicaciones/31963-masculinidad-factores-socioculturales-asociados-la-paternidad-estudio-cuatro. Accessed July 27, 2020.

48. Mota C, Aldana E, Gómez M. El hombre frente al embarazo y la pérdida perinatal: Una breve revisiónteórica. Departamento de Psicología del Instituto Nacional de Perinatología. [In: Spanish]. Alternativas en Psicología. 2018; 38: 44-60.

49. Ochoa M. Paternidad e Identidad Masculina en Costa Rica: El Sobredimensionamiento del Mandato de la Proveeduría. [In: Spanish]. Diálogos: Revista Electronica de Historia. 2004; 5(1): 1-24. doi: 10.15517/dre.v5i1-2.6236
50. Tonelli M, Beiras A, Lodetti A, De Lucca D, De Andrade MG, Araújo S. Cambios y permanencias: Investigando la paternidad en contextos de bajarenta. [In: Spanish]. Revista Interamericana de Psicología. 2006; 40(3): 303-312.

51. Parkes C. Bereavement as a psychosocial transition: Process of adaptation to change. In: Stroebe MS, Stroebe W, Hannson RO, eds. Handbook of Bereavement: Theory, Research, and Intervention. Cambridge, United Kingdom: Cambridge University Press; 1993: 91-101.

52. Nava R. Los hombres como padres en el distrito federal a principios de los noventa (Disertación doctoral). Universidad de UNAM; 1996.

53. Maldonado-Durán M, Sauceda-García J, Lartigue T. Cambiosfisiológicos y emocionalesdurante el embarazo normal y la conducta del feto. [In: Spanish]. Perinat Reprod Hum. 2008: 22(1): 5-14.

54. Naziri D, Dragonas T. Passage into paternity: A clinical approach. [In: Spanish].. La Psychiatrie de l'enfant. 1993; 37(2): 601-629.

55. Rodríguez A. Maternidad y paternidadtemprana: Una variable de medida para la percepción del reciénnacido. [In: Spanish]. Memoria de Licenciatura. 2001.

56. Schael D. Examining potential influences on paternal and maternal attachment: An early influence on learning. Human and Social Sciences. 2002; 62(8-A): 267-269.

57. Osores FNJ. Identidades masculinas: varones de clase media en el Perú [In: Spanish]. Lima, Perú: Pontificia Universidad Católica de Perú; Peru; 1997; 192.

58. Palacios E, Jadresic E. Aspectosemocionales en la fertilidad: Una revision de la literature reciente. [In: Spanish]. Revista Chilena de Neuro-psiquiatría. 2000; 38(2): 94-103. doi: 10.4067/S071792272000000200004

59. Theut S, Petersen F, Zaslow M, Cain R, Rabinovich B, Morihisa J. Perinatal loss and parental bereavement. Am J Psychiatry. 1989; 146: 635-639. doi: 10.1176/ajp.146.5.635

60. Lang A, Gottlieb L, Amsel R. Predictors of husbands' and wives' grief reactions following infant death. The role of marital intimacy. Death Stud. 1996; 20(1): 118-123. doi: 10.1080/07481189608253410

61. The Lancet. Acabando con las muertes intrauterinas prevenibles. [In: Spanish]; 2016. Web site. https://www.healthynewbornnetwork.org/resource/acabando-con-las-muertes-intrauterinas-prevenibles-un-resumen-ejecutivo-para-las-series-de-lancet/. Accessed July 27, 2020.

62. Conway K, Russell G. Couples' grief and experience of support in the aftermath of miscarriage. Br J Med Psychol. 2000; 73(4): 531-545. doi: 10.1348/000711200160714

63. Najman JM, Vance JC, Boyle F, Embleton G, Foster B, Thearle 
J. The impact of a child's death on marital adjustment. Social Science and Medicine. 1993; 37(8): 1005-1010. doi: 10.1016/02779536(93)90435-7

64. Gold K, Sen A, Hayward R. Marriage and co-habitation outcomes after pregnancy loss. Pediatrics. 2010; 125(5): e1202-e1207. doi: $10.1542 /$ peds.2009-3081

65. Koopmans L, Wilson T, Cacciatore J, Flenandy V. Support for mothers, fathers, and families after perinatal death. Cochrane Database Syst Rev. 2013; 6: 1-22. doi: 10.1002/14651858.CD 000452.pub

66. Shreffler K, Hill T, Cacciatore J. The impact of infertility, miscarriage, stillbirth, and child death on marital dissolution. Journal of Divorce and Remarriage. 2012; 53(2): 91-107.

67. Ridaura IP. Estudio del duelo perinatal: Interrupcionesmédicas del embarazo, muertesprenatales y muertes posnatales. [dissertation]. Universidad Autónoma de Barcelona; Bellaterra, Spain; 2015.

68. Buchi S, Morgeli H, Schnyder U, Jenewein J, Glaser A, Fauchere J, et al. Shared or discordant grief in couples two to six years after the death of their premature baby: Effects on suffering and posttraumatic growth. Psychosomatics. 2009; 50(2): 123-130. doi: 10.1176/appi.psy.50.2.123

69. Kamm S, Berg B. Grief communication, grief reactions, and marital satisfaction in bereaved parents. Death Stud. 2001; 25(7): 569-582. doi: 10.1080/07481180126576

70. Cacciatore J, Erlandsson K, Radestad I. Fatherhood and suffering: A qualitative exploration of Swedish men's experiences of care after the death of a baby. Int J Nurs Stud. 2013; 50: 664-670. doi: 10.1016/j.ijnurstu.2012.10.014

71. Barr P. Guilt and shame proneness and the grief of perinatal bereavement. Psychology and Psychotherapy: Theory, Research and Practice. 2004; 77(4): 493-510. doi: 10.1348/1476083042555442

72. Avelin P, Radestad I, Saflund K, Wrendling R, Erlandsson K. Parenatal grief and relationships after the loss of a stillborn baby. Midwifery. 2013; 29: 663-668. doi: 10.1016/j.midw.2012.06.007

73. Campbell-Jackson L, Bezance J, Horsch A. "A renewed sense of purpose": Mothers' and fathers' experience of having a child following a recent stillbirth. BMC Pregnancy Childbirth. 2014; 14: 423. doi: 10.1186/s12884-014-0423x

74. Cacciatore J, Barr P. Problematic emotions and maternal grief. Omega (Westport). 2007; 56(4): 331-348. doi: 10.2190/om.56.4.b

75. Van Den Berg PT, Wilderom CPM. Defining, measuring, and comparing organisational cultures. App Psychol. 2004; 53: 570-582. doi: 10.1111/j.1464-0597.2004.00189.x

76. O'Leary J, Thorwick C. Attachment to the unborn child and parental mental representations of pregnancy following perinatal loss. Attachment: New Directions of Psychotherapy and Relational Psychoa- nalysis. 2008; 2: 292-320.

77. Samuelsson M, Radestad I, Segesen K. A waste of life: Father's experience of losing a child before birth. Birth. 2013; 28: 124-130. doi: 10.1046/j.1523-536x.2001.00124.x

78. Arsenault D, Donato K. Restrained expectations in late pregnancy following loss. J Obstet Gynecol Neonatal Nurs. 2007; 36: 550557. doi: 10.1111/j.1552-6909.2007.00185.x

79. Turton P, Hughes P, Evans C, Fainman D. Incidence correlates, and predictors of post-traumatic stress disorder in the pregnancy after stillbirth. Br J Psychiatry. 2001; 178: 556-560. doi: 10.1192/ bjp.178.6.556

80. Grote N, Bridge J, Gavin A, Melville J, Lyengar, S, Katon W. A meta-analysis of depression during pregnancy and the risk of preterm birth, low birth weight and intrauterine growth restriction. Arch Gen Psychiatry. 2010; 6: 1012-1024. doi: 10.1001/archgenpsychiatry.2010.111

81. Glove V, Bergman K, Sarkar P, Connor O. Association between maternal and amniotic fluid cortisol is moderated by maternal anxiety. Psychoneuroendocrinology. 2009; 34: 430-435. doi: 10.1016/j.psyneuen.2008.10.005

82. Franche L. Psychologic and obstetric predictors of couples' grief during pregnancy after miscarriage or perinatal death. Obstet Gynecol. 2001; 97: 597-602. doi: 10.1016/s0029-7844(00)01199-6

83. American Psychiatric Association. Diagnostic and Statistical Manual of Mental Disorders. $5^{\text {th }}$ ed. 2013.

84. Cozza S, Fisher J, Ortiz C, Skritskaya N, Wall M, Fullerton C, et al. Performance of DSM- 5 persistent complex bereavement disorder criteria in a community sample of bereaved military family members. Am J Psychiatry. 2016; 173(9): 919-929. doi: 10.1176/ appi.ajp.2016.15111442

85. Shear K, Frank E, Houck P, Reynolds C. Treatment of complicated grief: A randomized controlled trial. JAMA. 2005; 293(21): 2601-2608.

86. Badenhorst W, Riches S, Turton P, Hughes P. Perinatal death and fathers. Journal of Psychosomatic Obstetrics \& Gynecology. 2007; 28(4): 193-198. doi: 10.1080/01674820701535340

87. Hughes P, Riches S. Psychological aspects of perinatal loss. Curr Opin Obstet Gynecol. 2003; 15(2): 107-111. doi: 10.1097/00001703200304000-00004

88. Korenromp M, Page-Christians G, Bout J, Mulder E, Hunfeld J, Potters C, et al. A prospective study on parental coping 4 months after termination of pregnancy for fetal anomalies. Prenat Diagn. 2007; 27(8): 709-716. doi: 10.1002/pd.1763

89. Radestad I, Surkan P, Steineck G, Cnattingius S, Onelov E, Dickman D. Long-term outcomes for mothers who have or have 
not held their stillborn baby. Midwifery. 2009; 25(4): 422-429. doi: 10.1016/j.midw.2007.03.005

90. Raphael M. Cancer detection in working women: A report on 7450 subjects. The Medical Journal of Australia. 1977; 2: 557-560. doi: 10.5694/j.1326-5377.1977.tb114640.x

91. Zisook S, Shuchter SR. The first four years of widowhood. Psychiatric Annals. 1986; 16(5): 288-294. doi: 10.3928/0048-571319860501-08

92. Peters M, Lisy K, Riitano D, Jordan Z, Aromataris E. Caring for families experiencing stillbirth: Evidence-based guidance for maternity care providers. Women Birth. 2015; 28: 272-278. doi: 10.1016/j.wombi.2015.07.003

93. Gómez A. Buscancrearprotocolo para el manejo de la pérdida de un bebé [In: Spanish]. El Nuevo Día. 2015; Web site. http:// www.endi.com. Accessed July 27, 2020.

94. Höglund B, Rådestad I, Hildingsson I. Few women receive a specific explanation of a stillbirth - an online survey of women's perceptions and thoughts about the cause o Hildingsson $\mathrm{f}$ their baby's death. BMC Pregnancy Childbirth. 2019; 19: 139. doi: 10.1186/ s12884-019-2289-4

95. Gold K, Kuznia A, Hayward R. How physicians cope with stillbirth or neonatal death: A national survey of obstetrician. Obstet Gynecol. 2008; 112: 29-34. doi: 10.1097/AOG.0b013e31817d0582

96. Waterman A, Garbutt J, Hazel E, Dunagan W, Levinson W, Fraser $\mathrm{V}$, et al. The emotional impact error on practicing physicians in the United States and Canada. Jt Comm J Qual Patient Saf. 2015; 33: 467-476. doi: 10.1016/s1553-7250(07)33050-x

97. West C, Huschka M, Novotny P, Sloan J, Kolars J, Habermann $\mathrm{T}$, et al. Association of perceived medical errors with resident distress and empathy: A prospective longitudinal study. JAMA. 2006; 296(9): 1071-1078. doi: 10.1001/jama.296.9.1071

98. The American College of Obstetricians and Gynecologists. Coping with the stress of medical professional liability litigation. Revised Committee Opinion. 2016; 551: 1-3. 